\title{
Corrigendum: Metastatic Extramammary Paget's Disease: Pathogenesis and Novel Therapeutic Approach
}

\section{OPEN ACCESS}

Approved by:

Frontiers in Oncology

Editorial Office,

Frontiers, Switzerland

*Correspondence:

Takeru Funakoshi

takeruf@a8.keio.jp

Specialty section:

This article was submitted

to Cancer Immunity and Immunotherapy,

a section of the journal

Frontiers in Oncology

Received: 19 February 2018 Accepted: 19 February 2018

Published: 12 March 2018

Citation:

Fukuda K and Funakoshi T (2018) Corrigendum: Metastatic Extramammary Paget's Disease:

Pathogenesis and Novel Therapeutic Approach. Front. Oncol. 8:47. doi: 10.3389/fonc.2018.00047
Keitaro Fukuda ${ }^{1,2}$ and Takeru Funakoshi ${ }^{2 *}$

${ }^{1}$ Department of Dermatology, University of Massachusetts Medical School, Worcester, MA, United States, ${ }^{2}$ Department of Dermatology, Keio University School of Medicine, Tokyo, Japan

Keywords: metastatic extramammary Paget's disease, HER2-PI3K/ERK signaling, lymphangiogenesis, CXCR4stromal cell-derived factor-1 axis, CD163+M2 macrophage, receptor activator of nuclear factor kappa-B ligand-RANK signaling, mismatch-repair deficient, anti-PD-1 antibody

\section{A corrigendum on}

Metastatic Extramammary Paget's Disease: Pathogenesis and Novel Therapeutic Approach by Fukuda K, Funakoshi T. Front Oncol (2018) 8:38. doi: 10.3389/fonc.2018.00038

In the published article, there was an error in the number of ongoing clinical trial for HER2-positive unresectable or metastatic EMPD “(UMIN-000006629)". Instead of “(UMIN-000006629)”, it should be "(UMIN000021311)". The authors apologize for this error and state that this does not change the scientific conclusions of the article in any way.

The original article has been updated.

Conflict of Interest Statement: The authors declare that the research was conducted in the absence of any commercial or financial relationships that could be construed as a potential conflict of interest.

Copyright (C) 2018 Fukuda and Funakoshi. This is an open-access article distributed under the terms of the Creative Commons Attribution License (CC BY). The use, distribution or reproduction in other forums is permitted, provided the original author(s) and the copyright owner are credited and that the original publication in this journal is cited, in accordance with accepted academic practice. No use, distribution or reproduction is permitted which does not comply with these terms. 